\title{
MODEL OF DEFECT FORMATION IN ANNEALED UNDOPED AND Fe-DOPED LIQUID ENCAPSULATED CZOCHRALSKI InP
}

\author{
Zhao Youwen, S. Fung, C. D. Beling. Xu Xiaoliang, and Gong Min \\ Department of Physics, The University of HongKong, HongKong, P. R. China \\ Sun Niefeng, Sun Tongnian, Chen Xudong, Zhang Ronggui, and Liu Silin \\ Hebei Semiconductor Research Institute, P. O. Box 179. Shijiazhuang, Hebei, P. R. China
}

\begin{abstract}
Infrared absorption spectroscopy measurements indicate high concentration of hydrogen indium vacancy complex $\mathrm{V}_{\mathrm{In}} \mathrm{H}_{4}$ in undoped and Fe-doped liquid encapsulated Crochralski (LEC) InP. Annealed undoped and Fe-doped semi-insulating (SI) InP are studied by room temperature Hall effect measurement and photocurrent spectroscopy. The results show that a mid gap donor defect and some shallow intrinsic defects are formed by high temperature annealing. This mid gap defect is shown to be phosphorus antisite related. Defect formation process and compensation mechanism in annealed SI InP are discussed.
\end{abstract}

\section{Introduction}

Undoped liquid encapsulated Czochralski (LEC) InP with low carrier concentration has been found to be annealed into semi-insulating (SI) material at temperature around $900^{\circ} \mathrm{C}[1-5]$. A few defects have been detected in annealed LEC $\operatorname{InP}[6,7]$. In annealed SI materials there are usually more defects than annealed materials with low resistivity $[8,9]$. These phenomena indicate that intrinsic defects have been formed by the annealing process, and this process is more complicated for annealed SI InP. Fe contamination or activation has also been found in annealed InP but the fact that $\mathrm{Fe}^{3+}$ cannot be detected in annealed undoped SI InP indicates that other mechanisms have to be considered[10]. Moreover, the phenomenon that horizontal gradient freeze (HGF) grown InP does not have this property|2] indicates that metal contamination such as $\mathrm{Fe}$ is not directly responsible for the thermal induced SI behavior. Thus, neither the defect formation process nor the compensation mechanism is well understood so far.

\section{Experimental}

Undoped LEC InP wafers with carrier concentration of $3-5 \times 10^{15} \mathrm{~cm}^{-3}$ and Fe-doped SI InP wafers are used for the annealing experiment. All wafer annealing is carried out in a phosphorus ambient of about $60 \mathrm{mbar}$ in quartz tube which is pumped to vacuum before it is sealed. Electrical parameters are measured by Hall effect at room temperature. Hydrogen indium vacancy complex $\mathrm{V}_{\mathrm{ln}} \mathrm{H}_{4}$ in the samples is detected by Fourier transform infrared absorption (FTIR) spectroscopy at room temperature and/or $20-30 \mathrm{~K}$. The energy levels of defects in annealed undoped and Fe-doped SI InP are detected by photocurrent spectroscopy at room temperature.

\section{Results and Discussion}

Some annealing results of undoped and Fedoped InP are listed in table 1 . It can be seen from the electrical parameters of annealed undoped InP that $\mathrm{n}$ type semi-insulating and mixing conduction InP can be obtained after the heat treatment. For Fe-doped SI InP, there are large changes in the elcctrical properties when it is annealed at different temperature or for different duration. These changes are generally related to the formation of intrinsic defects both in annealed undoped [7,9] 
and Fe-doped $\ln P[11,12]$. The formation of these intrinsic defects is usually correlated with the disappearance of a intrinsic defect in as-grown InP after annealing because residual impurity concentration can not be changed appreciably by this annealing process. In principle. there are a lot of intrinsic defects in as-grown InP. The fact that a shallow donor in undoped InP can be annihilated by short time annealing implies that this shallow donor should not be phosphorus vacancy related since phosphorus atom can not have so large a diffusion coefficent[13]. Besides, intrinsic defects such as vacancy or antisite, which are usually deep level defects, are of low concentration since deep level defect concentration in as-grown LEC InP is around the detection limit of deep level transient spectroscopy (DLTS) [14] or below that of optically detected magnetic resonance (ODMR) [15]

Table 1 Electrical parameters of annealcd LEC InP

\begin{tabular}{|c|c|c|c|c|}
\hline Dopant & $\begin{array}{c}\text { Temperature } \\
\left({ }^{\circ} \mathrm{C}\right)\end{array}$ & $\begin{array}{l}\text { Time } \\
(\mathrm{h})\end{array}$ & $\begin{array}{l}\text { Resistivity } \\
(\Omega . \mathrm{cm})\end{array}$ & $\begin{array}{l}\text { Mobility } \\
\left(\mathrm{cm}^{2} / \mathrm{ss}\right)\end{array}$ \\
\hline \multirow[t]{2}{*}{ undoped } & as-grown & & 0.48 & 3740 \\
\hline & 900 & 90 & $2.76 \times 10^{7}$ & 2710 \\
\hline \multirow[t]{2}{*}{ undoped } & as-grown & & 0.27 & 4320 \\
\hline & 900 & 90 & $1.05 \times 10^{6}$ & 28 \\
\hline \multirow[t]{7}{*}{ Fe-doped } & as-grown & & $1.92 \times 10^{7}$ & 1950 \\
\hline & 500 & 0.5 & $7.68 \times 10^{7}$ & 2250 \\
\hline & 600 & 0.5 & $6.41 \times 10^{7}$ & 2350 \\
\hline & 700 & 0.5 & $1.88 \times 10^{7}$ & 1700 \\
\hline & 700 & 12 & $8.15 \times 10^{4}$ & 1990 \\
\hline & 800 & 50 & $6.73 \times 10^{7}$ & 3250 \\
\hline & 900 & 50 & $7.85 \times 10^{3}$ & 3540 \\
\hline
\end{tabular}

On the other hand, a hydrogen indium vacancy complex $\mathrm{V}_{\text {in }} \mathrm{H}_{4}$ has been found in as grown LEC InP before annealing $[16,17]$ In all our undoped LEC InP samples, this hydrogen complex can be detected by FTIR at room temperature and/or 20$30 \mathrm{~K}[18,19]$. The concentration of $\mathrm{V}_{\mathrm{In}} \mathrm{H}_{4}$ was found to be compensation ratio dependent in undoped LEC InP and quite high in Fe-doped SI InP|19|. This fact provides the evidence that $\mathrm{V}_{\mathrm{in}} \mathrm{H}_{4}$ is a donor in agreement with the theory prediction| 111 . A surprising high concentration of $\mathrm{V}_{\mathrm{In}} \mathrm{H}_{4}$ in the range of $10^{15} \mathrm{~cm}^{-3} \sim 10^{16} \mathrm{~cm}^{-3}$ was also found in these samples[19]. This result is also consistent with the mass spectrometry analysis which reveals that in some cases the total acceptor impurity concentration is much higher than that of donor impurity in undoped $n$ type LEC InP[20]. Based on these experimental results, it is believed that the donor annihilated thermally in as grown LEC InP is mainly $\mathrm{V}_{\text {ln }} \mathrm{H}_{4}$ because its bond is weak and hydrogen atoms diffuse very quickly in all semiconductors[21]. The dissociation of $\mathrm{V}_{\ln } \mathrm{H}_{4}$ will leave isolated indium vacancies and more defect or defect complex can be formed.

As Hall effect measurement cannot supply us with more information about the defect in the annealed SI InP, room temperature photocurrent measurements are carried out on annealed undoped $\mathrm{SI}$ and $\mathrm{Fe}$-doped SI InP. All the photocurrent spectra can be found in reference [18]. In Fe-doped SI InP, in addition to the Fe related $0.66 \mathrm{eV}$ level a new mid gap level of $0.65 \mathrm{eV}$ appears when the sample is annealed at $600^{\circ} \mathrm{C}$ and $700^{\circ} \mathrm{C}$ for $30 \mathrm{~min}$. respectively. Further annealing of this sample at $700^{\circ} \mathrm{C}$ for 12 hours causes the $0.65 \mathrm{eV}$ peak intensity to become stronger than that at $0.66 \mathrm{eV}$ and the resistivity decreases to $8.5 \times 10^{4} \Omega \mathrm{cm}$. The decrease of resistivity of annealed Fe-doped InP is caused by the increase of shallow intrinsic defect concentration[11,12]. It is interesting that the SI property of this sample is recovered after it is annealed at $800^{\circ} \mathrm{C}$ and $900^{\circ} \mathrm{C}$ for about 50 hours. Although the photocurrent spectra of the latter two cases are not available, we can speculate from the $700^{\circ} \mathrm{C}$ annealing results that the $0.65 \mathrm{eV}$ mid gap level should dominate in the samples annealed at $800^{\circ} \mathrm{C}$ and $900^{\circ} \mathrm{C}$. Comparison with the photocurrent spectra of annealed Fe-doped SI InP, the $0.65 \mathrm{eV}$ peak is very strong and the $0.66 \mathrm{eV}$ peak is weak in the spectroscopy of undoped SI $\mathrm{InP}$. Combining these results with mass spectrometry result it can be concluded that the thermally produced $0.65 \mathrm{eV}$ defect is associated with phosphorus antisite which has been theoretically predicted to possess a mid gap donor level[22] similar to the well known $\mathrm{EL}_{2}$ in GaAs.

The formation process of phosphorus antisite defect can be expressed by the following cquations [18]:

$4 \mathrm{~V}_{\mathrm{ll}} \mathrm{H} \mathrm{H}_{1 .}{ }^{\circ}+10 \mathrm{e} \rightarrow \mathrm{V}_{\mathrm{ln}} \mathrm{H}_{3}+\mathrm{V}_{\mathrm{tn}} \mathrm{H}_{2}{ }^{-}+\mathrm{V}_{\mathrm{mn}} \mathrm{H}^{2-}+\mathrm{V}_{\mathrm{ln}}{ }^{3-}+10 \mathrm{H}^{0} \uparrow(\mathrm{I})$

$\mathrm{P}_{\mathrm{p}}+\mathrm{P}_{\mathrm{i}}+\mathrm{V}_{\mathrm{h}}{ }^{3-} \rightarrow \mathrm{P}_{\mathrm{ln}}^{2+}+\mathrm{V}_{\mathrm{p}}{ }^{+}+6 \mathrm{e}$ 
These two equations give the general process of the thermal dissociation of $\mathrm{V}_{\mathrm{ln}} \mathrm{H}_{4}$ and formation of phosphorus antisite defect. It is speculated that hydrogen complexes in equation (1) decompose completely upon high temperature annealing and leave large quantity of isolated indium vacancies allowing phosphorus antisites and other defects to be formed. The thermal dissociation of $\mathrm{V}_{\mathrm{In}} \mathrm{H}_{4}$ can be evidenced by the disappearance of $2315 \mathrm{~cm}^{-1}$ absorption peak in the FTIR spectroscopy of annealed InP[18]. Phosphorus antisite defect was also detected in high concentration in annealed high resistivity undoped LEC InP by the use of ODMR in 1986[23]. The spectrum also shows a strong photocurrent peak at $1.43 \mathrm{eV}$ for undoped SI InP[18]. This corresponds to the transition from a mid gap level to conduction band minimum $L^{c}$. This result gives the further evidence that high concentration of mid gap level defect has been formed. Other shallow intrinsic defects with energy level in the range of $0.4 \mathrm{eV}-0.56 \mathrm{eV}$ can also be found in the same spectrum. Defect energy level in the range of $0.1 \mathrm{eV}-0.3 \mathrm{eV}$ can not be detected due to the limitation of our instrument. The fact that phosphorus antisite level is nearly at same energy as that for $\mathrm{Fe}$ in $\mathrm{InP}$ means it is very difficult to distinguish former by DLTS and photo induced transient current spectroscopy (PICTS). The Fe related peak in annealed undoped or lightly $\mathrm{Fe}$ doped SI InP can be detected by PICTS but sometimes a negative peak appears in undoped SI InP and no mid gap level signal is observed[8]. Incidentally, this phenomenon usually happens in LEC SI GaAs which prevents $E_{2}$ from being detected. However, phosphorus antisite defect and $\mathrm{Fe}$ acceptor level can be distinguished clearly by our room temperature photocurrent spectroscopy.

It can be seen from the photocurrent spectra of annealed Fe-doped $\operatorname{InP}$ that the concentration of phosphorus antisite defect depends on the annealing temperature and time. This result indicates that moderate high temperature and long time annealing is necessary for the formation of the $0.65 \mathrm{eV}$ lcvel. High concentration of $\mathrm{V}_{\mathrm{ln}} \mathrm{H}_{4}$ is an important factor and condition for the realization of undoped SI InP by annealing. Fortunately, the concentration of
$\mathrm{V}_{\mathrm{In}} \mathrm{H}_{4}$ increases with increasing compensation ratio[19] implying that as-grown LEC InP lightly doped with shallow or deep acceptor impurity could be a method for the preparation of annealed undoped SI InP. Some annealing results can support this conclusion $[5,9]$ and it is believed that antisite defect dominates in many cases. It should be pointed out that the concentration of $\mathrm{V}_{\mathrm{In}} \mathrm{H}_{4}$ also depends on the growth condition of LEC InP and further investigations into this are required. In many cases as-grown LEC InP is not "real" $\mathrm{n}$ type due to the existence of $\mathrm{V}_{\mathrm{In}} \mathrm{H}_{4}$.

When both $\mathrm{Fe}$ and phosphorus antisite defect are present, the compensation in SI InP is relatively complicated. Basically, if phosphorus antisite or $\mathrm{Fe}$ dominates depend on the concentration of each of them and that of net shallow impurity concentration. This situation can also be found in SI GaAs when both $\mathrm{EL}_{2}$ and $\mathrm{Cr}$ are present. Most of the $\mathrm{Cr}$ centres are in $\mathrm{Cr}^{2+}$ state if the concentration of $\mathrm{EL}_{2}$ is high[24]. For annealed undoped SI InP, in many cases the concentration of phosphorus antisite could be higher than that of $\mathrm{Fe}$ because the concentration of $\mathrm{V}_{\mathrm{In}} \mathrm{H}_{4}$ in as-grown undoped $\mathrm{InP}$ is around $10^{15} \mathrm{~cm}^{-3}-10^{16} \mathrm{~cm}^{-3}$ while $\mathrm{Fe}$ contamination is only about $10^{15} \mathrm{~cm}^{-3}$. This can be supported by the fact that residual $\mathrm{Fe}$ in undoped SI InP is all in $\mathrm{Fe}^{2+}$ state since $\mathrm{Fe}^{3+}$ can not be detected[10]. In addition, many similarities can be found between annealed undoped SI LEC InP and as-grown LEC SI GaAs[25] either in the quantities of dcfect or the changes of intrinsic defect under different conditions. This is also an indication that intrinsic defects including phosphorus antisite defect have been formed in the annealing process.

\section{Conclusion}

Hydrogen indium vacancy complex $\mathrm{V}_{\mathrm{In}} \mathrm{H}_{4}$ is a main defect in as grown LEC InP with concentration in the range of $10^{15} \mathrm{~cm}^{-3}$ to $10^{16} \mathrm{~cm}^{-3}$ depending on the compensation ratio. The dissociation of this complex upon annealing is the origin of the formation of intrinsic defects including phosphorus antisite defect in annealed undoped and Fe-doped LEC InP. In many cases, phosphorus antisite defect in annealed undoped SI InP is the 
dominant compensation center. As-grown LEC InP predoped with shallow acceptor impurity and accompanied by annealing under moderate conditions is a promising method for the preparation of SI InP.

\section{References}

[1] D. Hofmann, G. Müller, and N. Streckfuss, Appl. Phys. A48, 315(1989)

[2] G. Hirt, D. Hofmann, F. Mosel, N. Schafer, and G. Müller, J. of Electron. Materials 20, 1065(1991)

[3] K. Kainosho, H. Shimakura, H. Yamamoto, and O. Oda, Appl. Phys. Lett. 59, 932(1991)

[4] R. Fornari, A. Brinciotti, E. Gombia, R. Mosca, and A. Sentiri, Mater. Sci. Eng. B28, 95(1994)

[5] A. Hruban, St. Strzelecka. W. Wegner, M. Gladysz. W. Orlowski, M. Piesa, and A. Mirowska, Proc. $8 \mathrm{th}$ Conf. On Semi-insulating III-V materials. Warsaw, Poland 1994, Ed. M. Goldewski (World Scientific, Singapore, 1994), p.43

[6] G. Hirt, D. Wolf, and G. Müller, J. Appl. Phys. 74, 5538(1993)

[7] G. Hirt, T. Mono, and G. Müller, Mater. Sci. Eng. B28, 101(1994)

[8] G. Marrakchi, K. Cherkaoui, A. Karoui, G. Hirt, and G. Müller, J. Appl. Phys. 79, 6947(1996)

[9] R. Fornari, A. Zappettini, E. Gombia, R. Mosca, K. CherKaoui, and G. Marrakchi, J. Appl. Phys, 81, 7604(1997)

[10] T. Wolf, D. Bimberg. G. Hirt. D. Hofmann. and G. Müller, Proceedings of the $4^{\text {th }}$ International conference on InP and Relaled Matcrials. Newport. USA, 1992, p.630

[11] H. J. von Bardeleben, D. Stievenard, K. Kainosho, and O. Oda, J. Appl. Phys. 70, 7392(1991)

[12] A. Kalboussi, G. Marrakchi, G. Guillot, K. Kainosho, and O. Oda, App. Phys. Lett. 61, 2583(1992)

[13] P. Kipfer, J. Lindolf. D. Hofmann. and G. Müller, J. AppL Phys. 69, 3860(1991)

[14] W. A. Aderson and K. L. Jiao. InP and Related Materials: processing, technology and devices, Ed. Avishay Katz (Artech house, Boston. 1992 ), p.83

[15] M. Deiri, A. Kana-ah. B. C. Cavenctt. T.A Kennedy, and N. D. Wilsley, Semicond. Sci. Technol. 3,706(1988)

[16] R. Darwich, B. Pajot, B. Rose, D. Robein, B. Theys, R. Rahbi, C. Porte, and F. Gendron, Phys. Rev. B48, 17776(1993)

[17] C. P. Ewels, S. Öberg, R. Jones, B. Pajot, and P. R. Briddon, Semicond. Sci. Technol. 11,502(1996)
[18] Y. W. Zhao, X. L. Xu, M. Gong, S. Fung, C. D. Beling, X. D. Chen, N. F. Sun, T. N. Sun, S. L. Liu, G. Y. Yang, X, B, Guo, Y. Z. Sun, L. Wang, Q. Y. Zheng, Z. H. Zhou, and J. Chen, Appl. Phys. Lett.( to be published)

[19] S. Fung, Y. W. Zhao, C. D. Beling, X. L. Xu, M. Gong, N. F. Sun, T. N. Sun, X. D. Chen, S. L. Liu, J. J. Qian, M. F. Sun, and X. L Liu, Appl. Phys. Lett. (submitted)

[20] S. Tong-nien, L. Szu-lin, and K. Shu-tseng, Proc. $2^{\text {nd }}$ Conf. On Semi-insulating III-V Materials, Evian, France 1982, Ed. Sherif Makram-Ebeid and Brian Tuck (Shiva, UK, 1982), p.61

[21] Hydrogen in Semiconductors, Semiconductors and Semimetals, Vol.38, Ed. J. I. Pankov and N. M. Johnson (Academic, London, 1991)

[22] A. P. Seitsonen, R. Virkkunen, M. J. Puska, and R. M. Nieminen, Phys. Rev. B49, 5253(1994)

[23] T. A. Kennedy, N. D. Wilsey, P. B. Klein, and R. L. Henry, Mater. Sci. Forum. Vol. 10-12, 271(1986)

[24] A. Goltzene, C. Schwab, and G. M. Martin, Semiinsulating III-V Materials, Nottingham, 1980 Ed. G. J. Rees (Shiva. UK, 1980), p.221

[25] D. C. Look, Imperfections in III/V Materials, Semiconductors and Semimetals, Vol.38, Edited by E. R. Weber (Academic, London, 1990) 